\title{
Globalisasi dan Perubahan Budaya: Perspektif Teori Kebudayaan Modern
}

\author{
I Gusti Ngurah Mayun Susandhika \\ Fakultas Ilmu Sosial dan Ilmu Politik \\ ngurah_yun@yahoo.co.id
}

\begin{abstract}
Makalah ini membahas relevansi teori budaya untuk memahami globalisasi dan perubahan budaya yang terjadi di Indonesia. Isu globalisasi dan perubahan budaya baru-baru ini menonjol dalam berbagai wacana di Indonesia, terutama dalam kaitannya dengan pertanyaan tentang bagaimana Indonesia adalah identitas budaya yang harus dijaga dalam menghadapi proses global seperti itu. Makalah ini berpendapat bahwa teori budaya kontemporer dapat membantu kita memahami konsep-konsep seperti budaya nasional dan identitas bukan sebagai entitas statis, esensialis, melainkan sebagai konstruksi sosial yang dinamis yang terus direproduksi dan diinovasi oleh subyek individu. Argumen seperti itu dikemukakan dalam makalah ini dengan memperkenalkan aspek-aspek teori budaya yang belum mendapat banyak perhatian di Indonesia, yaitu praktik, proses, konteks dan wacana tentang konstruksi budaya.
\end{abstract}

Kata kunci: Budaya, Globalisasi

Abstract - This paper discusses the relevance of culture theories for understanding globalization and cultural change taking place in Indonesia. The issue of globalization and cultural change has recently figured prominently in various discourses in Indonesia, especially in relation to the question of how Indonesia is cultural identities should be maintained in the face of such a global process. This paper argues that the contemporary culture theory can help us understand such concepts as national culture and identity not as a static, essentialist entity, but rather as a dynamic social construction that is continuously reproduced and innovated by individual subjects. Such an argument is put forth in this paper by introducing aspects of culture theory that have not received much attention in Indonesia, i.e. practice, process, context and discourse concerning cultural construction.

Keywords: culture, globalization

\section{PENDAHULUAN}

Makalah ini bertujuan membahas masalah "Globalisasi dan Perubahan Budaya" dari perspektif teori kebudayaan yang telah berkembang dalam Antropologi secara khusus menyoroti teori-teori kebudayaan mutakhir dan modern. Modern semakin berkembang menjadi acuan penelitian ini.

Antropologi adalah suatu displin ilmu yang telah lama berusaha merumuskan konsep kebudayaan sebagai salah satu konstruksi teoritis utama dalam penelitian sosial. Mulai dari definisi kebudayaan "klasik" seperti yang berasal dari Tylor, yang melihat kebudayaan sebagai "suatu kesatuan kompleks yang terdiri dari pengetahuan, kepercayaan, hukum, moralitas, dan adat-istiadat", hingga pendekatan interpretatif Clifford Geertz yang mencoba mempertajam pengertian kebudayaan sebagai "pola-pola arti yang terwujud sebagai simbol-simbol yang diwariskan secara historis......... dengan bantuan mana manusia mengomunikasikan, melestarikan, dan mengembangkan pengetahuan serta sikap terhadap hidup" (1973: 89), teori-teori kebudayaan telah memberi berbagai sumbangsih bagi pemahaman kehidupan sosial.

Dalam perkembangannya di Indonesia, Antropologi juga telah menghasilkan beragam teori kebudayaan. Koentjaraningrat (1985: 180), misalnya pada dekade 1970-an mendefinisikan kebudayaan sebagai keseluruhan sistem gagasan, tindakan dan hasil karya manusia dalam rangka kehidupan masyarakat yang dijadikan milik manusia dengan belajar. Di awal dekade 
1980-an Parsudi Suparlan (1986) mencoba melihat kebudayaan sebagai pengetahuan yang bersifat operasional, yaitu sebagai keseluruhan pengetahuan yang dipunyai oleh manusia sebagai makhluk sosial; yang isinya adalah perangkat-perangkat dan model-model pengetahuan yang secara selektif dapat digunakan untuk memahami dan menginterpretasi lingkungan yang dihadapi; dan untuk mendorong dan menciptakan tindakan-tindakan yang diperlukannya.

Dalam membahas masalah "Globalisasi dan Perubahan Budaya" makalah ini akan menyoroti teori-teori kebudayaan mutakhir yang berkembang setelah tampilnya pendekatan interpretatif Geertz maupun definisi kebudayaan yang operasional seperti dikemukakan Suparlan. Teori-teori kebudayaan demikian, yang sering dijuluki beragam sebutan seperti "post-modernis", "post-strukturalis", "repleksif", dan lainlain, berusaha menghindari esensialisme dan reifikasi dalam penggambaran suatu kebudayaan, dengan menekankan berbagai aspek kebudayaan yang sebelumnya kurang menonjol dalam bahasan Antropologis, seperti: (1) wacana (eg. Foucault, 1980; Said, 1978); (2) praksis (Alam, 1995a, 1995b, 1997; Bourdieu, 1977); (3) proses (Moore, 1987); dan (4) kebudayaan sebagai konteks (Keesing, 1994; Sahlins, 1994).

Teori-teori kebudayaan demikian membantu kita memahami secara lebih rinci implikasi proses "Globalisasi dan Perubahan Budaya" yang sering menjadi pokok bahasan di negeri kita dewasa ini. Misalnya saja, studi-studi antropologis yang bertumpu pada teori-teori ini menunjukkan bahwa proses globalisasi bukanlah suatu proses yang baru mulai akhir-akhir ini, yang disebabkan oleh lonjakan perkembangan sistem komunikasi, tapi sejak masa lalu setiap masyarakat di muka bumi ini merupakan suatu "masyarakat global" (Sahlins, 1994: 397). Begitu juga, kemajemukan kebudayaan terwujud bukan karena terisolasinya kelompok-kelompok sosial, melainkan justru karena adanya kontak secara terus-menerus antara kelompok-kelompok tersebut (Lévi-Strauss, dikutip dalam Sahlins, 1994: 387).

Temuan-temuan demikian mengajarkan kita bahwa proses "Globalisasi dan Perubahan Budaya" tidak perlu dihadapi dengan sikap menutup diri yang ekstrim.
Sebaliknya, dengan memahami bagaimana kebudayaan itu dikonstruksi melalui wacana dan praksis, misalnya dapat memanfaatkan proses globalisasi sebagai sarana untuk memperkaya kemajemukan kebudayaan-kebudayaan di Indonesia.

\section{PRAKSIS, PROSES, DAN KONTEKS}

Pendekatan interpretatif Clifford Geertz yang melihat kebudayaan sebagai "suatu sistem konsepsi yang diwariskan (dari generasi sebelumnya) dan diekspresikan dalam bentuk simbolik; dengan bantuan kebudayaan manusia mengomunikasikan, mengabadikan, dan mengembangkan pengetahuan dan sikap terhadap kehidupan (1973: 89)" telah banyak memengaruhi kajian-kajian Antropologi sejak tahun 1970-an hingga pertengahan 1980an.

Berdasarkan konsep kebudayaan demikian, dalam pendekatan interpretatif Geertz "agama" misalnya diteliti sebagai suatu "sistem kebudayaan" yang didefinisikan sebagai "suatu sistem simbol yang bertindak untuk meningkatkan suasana hati (moods) dan motivasi (motivations) yang kuat, mendalam dan bertahan lama, dengan cara memformulasikan konsepsi-konsepsi mengenai tatanan dasar alam dan kehidupan, dengan menyelimuti konsepsi-konsepsi tersebut dengan suatu suasana yang faktual sehingga suasana hati dan motivasi yang ditimbulkannya terasa nyata" (1973: 90).

Walaupun pendekatan interpretatif demikian telah memberikan sumbangsih besar dalam memperkaya pengertian kita akan makna-makna yang terkandung dalam kehidupan sosial dan kehidupan beragama pada umumnya, kelemahan-kelemahannya telah banyak dikritik sejak pertengahan tahun 1980-an (eg. Clifford, 1988: 40 -41; Crapanzano, 1988; Shankman, 1984). Salah satu kritik yang paling tajam dalam mengungkapkan kelemahan konsep kebudayaan Geertz adalah yang dikemukakan oleh Asad (1983).

Kritik Asad sebenarnya ditujukan kepada definisi agama Geertz, namun kritiknya juga mengungkapkan kelemahan konsep kebudayaannya. Menurut Asad (1983: 50), walaupun definisi agama yang dikemukakan oleh Geertz sangat kaya dalam menggambarkan bagaimana agama membentuk pengetahuan dan sikap manu- 
sia terhadap hidup, definisi ini sama sekali tidak menyinggung proses sebaliknya, yaitu bagaimana kehidupan manusia memengaruhi, mengondisikan, dan membentuk simbol-simbol keagamaan. Dengan kata lain, definisi agama yang demikian menggambarkan hubungan antara simbol-simbol keagamaan dan kehidupan sosial sebagai suatu "hubungan satu arah" di mana simbol-simbol keagamaan yang menginformasikan, memengaruhi, dan membentuk kehidupan sosial. Dengan melihat simbol-simbol keagamaan sebagai suatu yang sui generis, sama sekali tidak ditunjukkan dalam definisi Geertz ini bagaimana perspektif keagamaan dipengaruhi oleh pengalaman-pengalaman manusia dalam kehidupan sehari-hari. Lebih lanjut Asad mengemukakan bahwa kelemahan utama pendekatan Geertz ini disebabkan oleh definisi kebudayaan sebagai "suatu totalitas arti yang bersifat a priori (seolah-olah diterima "jadi" dari generasi sebelumnya), yang sama sekali dipisahkan dari proses pembentukan kekuasaan dan efek-efeknya" (a notion of culture as an a priori totality of meanings, divorced from processes of formation and effects of power) (Asad, 1983: 251). Sebagai akibat dari konsepsi kebudayaan demikian, menurut Asad terwujudlah dalam pendekatan Geertz "jurang pemisah" (hiatus) antara "sistem kebudayaan" dan "realitas sosial" (1983: 252).

Konsep teoritis yang mencoba mengisi kelemahan definisi kebudayaan demikian adalah konsep practice, yang dalam makalah ini diterjemahkan sebagai "praksis". Konsep ini dikemukakan oleh Bourdieu (1977) pada akhir tahun 1970-an, tetapi mulai menarik perhatian para antropolog baru pada pertengahan tahun 1980-an (eg. Moore, 1987; Ohnuki-Tierney, 1995; Ortner, 1984), bahkan ada artikel yang secara eksplisit membandingkan konsep kebudayaan Geertz dan Bourdieu (Lee, 1988).

Dalam presentasi ini tidak dapat diberikan uraian rinci mengenai teori praksis Bourdieu karena terbatasnya waktu. Pokok pikiran teori praksis yang paling relevan dalam pembahasan ini adalah bahwa konsep "praksis" (practice) Bourdieu dibedakan dari konsep "tindakan" (action) yang merupakan salah satu konstruksi teoritis utama sosiologi Weber, yang diwariskan dalam pendekatan interpretatif Geertz (Mengenai hubungan antara tradisi sosi- ologi Weber dan pendekatan interpretatif Geertz, lihat tulisan James Peacock berjudul "The Third Stream: Weber, Parson, Geertz" (1981)). Berbeda dengan konsep tindakan yang dalam tradisi sosiologi Weber cenderung dilihat sebagai pencerminan ide-ide yang terkandung dalam kebudayaan si pelaku, konsep praksis menekankan adanya hubungan timbal balik antara si pelaku dan apa yang oleh Bourdieu disebut sebagai "struktur objektif" yang mencakup juga "kebudayaan" sebagai sistem konsepsi yang diwariskan dari generasi ke generasi (Bourdieu, 1977: 83). Bourdieu menggambarkan hubungan timbal balik di antara keduanya sebagai (1) struktur objektif direproduksi secara terus-menerus dalam praksis para pelakunya yang berada dalam kondisi historis tertentu; (2) dalam proses tersebut para pelaku mengartikulasikan dan mengapropriasi simbol-simbol budaya yang terdapat dalam struktur objektif sebagai tindakan strategis dalam konteks sosial tertentu; (3) sehingga proses timbal balik secara terus-menerus antara praksis dan struktur objektif dapat menghasilkan baik perubahan maupun konstinuitas.

Pemahaman konsep praksis sesungguhnya memerlukan pembahasan konsep-konsep Bourdieu lainnya, seperti habitus, doxa, dan lain-lain, namun hal itu tidak dapat dilakukan dalam presentasi ini. Implikasi utama dari konsep praksis seperti yang dijabarkan di atas, khususnya bagi konsep kebudayaan, ialah bahwa simbol-simbol maupun konsepsi-konsepsi yang terkandung dalam suatu kebudayaan senantiasa bersifat cair, dinamis, dan sementara, karena keberadaannya tergantung pada praksis para pelakunya yang berada pada konteks sosial tertentu, yang sudah barang tentu mempunyai "kepentingan" tertentu. Kebudayaan dalam arti ini merupakan suatu konstruksi sosial yang berkaitan erat dengan kepentingan maupun kekuasaan yang dimiliki si pelaku. Pengertian kebudayaan sebagai praksis seperti ini sama sekali tidak terungkap dalam pendekatan interpretatif yang telah lama mendominasi kajian-kajian antropologis.

Implikasi lainnya dari konsep kebudayaan demikian adalah bahwa kebudayaan sebagai senantiasa terwujud sebagai proses; proses interaksi timbal balik antara si pelaku dan simbol-simbol budaya dalam upaya si pelaku untuk mengartikulasikan 
dan mengapropriasikan simbol-simbol tersebut demi kepentingannya.

Terakhir, kebudayaan yang terwujud sebagai praksis dan proses akan juga berfungsi sebagai "konteks" bagi tindakan si pelaku. Kebudayaan dalam arti konteks seperti ini menawarkan sejumlah konsepsi yang menjadi bahan pertimbangan si pelaku dalam menentukan tindakannya.

\section{WACANA}

Pembahasan konsep kebudayaan dari segi teori praksis di atas mencoba mengungkapkan kelemahan pendekatan kebudayaan yang banyak memengaruhi kajian-kajian Antropologi hingga dewasa ini. Aspek lain konsep kebudayaan yang masih sangat jarang disinggung dalam kajian-kajian Antropologi di Indonesia adalah hubungan antara kebudayaan dan wacana (discourse).

Lepas dari berbagai orientasi teoritis yang terdapat dalam disiplin Antropologi, hampir semua teori-teori kebudayaan yang dikemukakan dalam Antropologi melihat kebudayaan sebagai suatu kenyataan empiris. Apakah kebudayaan itu dilihat sebagai gagasan, tindakan, atau hasil tindakan, Antropologi senantiasa melihatnya sebagai suatu kenyataan empiris yang dapat diamati, dimengerti atau pun diinterpretasi oleh si peneliti. Apa yang belum terjamah dalam perspektif seperti ini ialah dimensi kebudayaan sebagai wacana. Pendekatan praksis seperti yang diuraikan di atas mengandung implikasi bahwa kebudayaan selalu terwujud dalam praksis, dan salah satu praksis yang berfungsi mereproduksi kebudayaan adalah praksis kewacanaan (discursive practice).

Perspektif demikian mempunyai suatu perbedaan tajam dengan sudut pandang konvensional yang semata-mata melihat kebudayaan sebagai kenyataan empiris, karena pendekatan ini mengisyaratkan bahwa tulisan-tulisan Antropologi seperti etnografi pada dasarnya tidak lebih dari suatu bentuk wacana tentang kebudayaan, yang dalam aspek konstruksi sosial tidak beda efeknya dari wacana tentang kebudayaan yang muncul dalam dunia politik, ekonomi, sastra, seni, iptek, dan lain-lain. Perbedaan antara jenis-jenis wacana tersebut bukan dalam "objektivitas"nya, tetapi dalam audiencenya.

Wacana adalah suatu bentuk penuturan verbal yang berkaitan erat dengan "kepentingan" si penutur, sehingga dapat merupakan suatu akumulasi konsep ideologis yang didukung oleh tradisi, kekuasaan, lembaga, dan berbagai macam modus penyebaran pengetahuan (Foucault, 1980). Perlu diperhatikan bahwa dalam arti adanya keterlibatan "subjektivitas" demikian, wacana dibedakan dari "teks" yang merupakan penuturan verbal yang telah lepas dari posisi si penutur.

Dengan pengertian wacana demikian, kita dapat melihat bahwa setiap wacana tentang kebudayaan juga tidak terlepas dari "kepentingan" dan "kekuasaan". Yang dimaksud dengan "kekuasaan" dalam presentasi ini bukanlah semata-mata kekuasaan politik, namun kekuasaan dalam arti power seperti yang dimaksud oleh Foucalt, kekuasaan yang dapat beredar. Kemudian dalam satu masyarakat pun dapat dijumpai berbagai macam wacana tentang kebudayan masyarakat bersangkutan yang dapat saja saling bertentangan, namun dengan mendapat dukungan dari kekuasaan, wacana tertentu dapat menjadi wacana yang dominan.

Walaupun wacana-wacana Antropologis mengenai kebudayaan juga tidak terlepas dari kepentingan-kepentingan tertentu seperti kepentingan akademis, karier, dan lain-lain. Wacana Antropologis dapat memberi konstribusi tersendiri dengan membeberkan adanya kepentingan-kepentingan tertentu dalam setiap wacana kebudayaan, dan menggambarkan bagaimana kepentingan-kepentingan tersebut ikut mewarnai isi dari setiap wacana.

\section{GLOBALISASI DAN PERUBAHAN BUDAYA}

Pengertian kebudayaan dari segi praksis dan wacana seperti ini membawa implikasi cukup berarti bagi pemahaman suatu gejala sosial budaya yang dewasa ini sering kita sebutkan proses "globalisasi". Dengan memahami kebudayaan sebagai praksis dan wacana, maka kebudayaan tampak sebagai, seperti apa yang dikatakan oleh Umar Kayam, "sebuah proses, sosoknya bersifat sementara, cair, dan tanpa batas-batas yang jelas" (Kompas, 2 Agustus 1995). Dalam arti ini, perbedaan antara kebudayaan "modern" dan "tradisional"; "asing" dan "pribumi"; "barat" dan "timur"; "asli" dan "campuran" hanyalah merupa- 
kan perbedaan-perbedaan yang semu dan sementara.

Kajian-kajian Antropologis dewasa ini telah banyak sekali mengungkapkan contoh-contoh di mana bentuk-bentuk kebudayaan yang dianggap sebagai suatu yang "asli" ternyata merupakan hasil konstruksi sosial yang terjadi dalam konteks sosial tertentu dengan mengacu kepada kebudayaan "asing". Tari kecak yang kini kita kenal sebagai bentuk tari "tradisional" Bali, menurut Vickers (1989) dan Yamashita (1992) merupakan hasil kreasi pelukis Barat Walter Spies yang mengombinasikan tari Sanghyang dengan motif cerita Ramayana pada dasawarsa 1930-an. Penelitian yang dilakukan oleh Laurie J. Sears mengungkapkan bahwa wayang kulit Jawa baru dianggap mengandung filsafat bertaraf tinggi setelah adanya kontak dengan gerakan teosofi barat pada tahun 1910 -- 1920 (Kompas, 15 Agustus 1997). Konsep kewanitaan Jepang, yang secara umum dikenal dengan istilah "ryosai kenbo" (isteri baik, ibu bijaksana, yang seringkali dianggap sebagai konsep kewanitaan khas Jepang yang membentuk karakter wanita Jepang yang setia, penurut, dan lain-lain. Ternyata adalah konsep yang dibuat dan dipopulerkan oleh pemerintah Meiji dengan mengombinasikan ajaran Konfusianisme dan nilai-nilai rumah tangga Eropa Barat abad ke-19 untuk memajukan proses industrialisasi (Tamanoi, 1990: 26).

Semua contoh ini menujukkan bahwa sesungguhnya proses globalisasi bukanlah suatu proses yang baru dimulai akhir-akhir ini, setelah menyebarnya internet, TV kabel, dan slogan pasar bebas yang berkaitan dengan program APEC. Seperti pernyataan Sahlins yang dikutip di atas, setiap mas-

\section{DAFTAR KEPUSTAKAAN}

Alam, Bactiar. 1995a. Diverging Spirituality: Religious Processes in A Northem Okinawan Village. Ph.D. Dissertation, Departement of Anthropology. Harvad University: Cambridge, Massachusetts.

1995b. Okinawa no Amercianization saikoosatsu [Rethinking the "Americanization" of Okinawa]. Shisò no kagaku 33: 19-32. yarakat di muka bumi ini pada dasarnya merupakan suatu "masyarakat global" (Sahlins, 1994: 387). Keistimewaan kondisi sosial dewasa ini dengan segala macam perangkat komunikasi dan informasi mutakhir bukan terletak pada kadar maupun intensitas proses globalisasi, tetapi pada kejelasan, keterbukaan, dan sifat "kasat mata" pengaruh berbagai macam kebudayaan dunia. Proses globalisasi sudah ada sejak dulu dan tak pernah absen dari kehidupan kita. Indonesia pada masa lalu, pada zaman kerajaan Sriwijaya, Majapahit atau pun pada masa kolonial, selalu merupakan masyarakat kosmopolitan di mana pengaruh kebudayaan mancanegara dari India, Cina, Arab, maupun Eropa menemukan tempat persemaian yang subur.

Sumbangsih yang dapat diberikan oleh Antropologi dalam menghadapi era seperti ini adalah dengan mengungkapkan kodrat setiap kebudayaan yang bersifat dinamis, cair dan hybrid dengan menghindari serta mengkritik representasi budaya yang bersifat esensialis dan statis. Dengan semakin sadar akan karakteristik dinamika kebudayaan yang demikian, kita pun akan menjadi sadar bahwa proses globalisasi dan perubahan budaya tak pernah absen dari kehidupan sosial manusia. Seperti dikatakan Lévi-Strauss, identitas atau jati diri para pendukung suatu kebudayaan menjadi kuat bukan karena isolasi tetapi justru karena adanya interaksi antara budaya. Maka kewaspadaan akan hilangnya jati diri dalam proses globalisasi tak perlu menjadi kekhawatiran berlebiha yang menjurus pada xenophobia. Karena kontinuitas budaya, seperti dikemukakan oleh Sahlins (1994: 389), justru terwujud sebagai modus perubahan budaya.

1997. Cultural and Religious Identities in Okinawa Today: A Case Study of the Seventh-day Adventist Proselytization in A Northem Okinawa Village. Nippon (2) 5: 5-22.

Asad, Talal. 1983. "Antropological Conceptions of Religion: Reflection on Geertz". Man 18 (2): 237-259.

Bourdieu, Pierre. 1977. Outline of a Theory of Practice. Cambridge, England: Cambridge University Press. 
Clifford, James. 1988. The Predicament of Culture: Twentieth-Century Ethnography, Literature, and Art. Cambridge, Massachusetts: Harvard University Press.

Crapanzano, Vicent. 1986. 'Hermes' Dilemma', dalam James Clifford (ed.). The Predicament of Culture: Twentieth-Century Ethnography, Literature, and Art. Cambridge, Massachusetts: Harvard University Press.

Foucault, Michel. 1972. Power/Knowledge. New York: Pantheon.

Geertz, Clifford. 1973. The Interpretation of Cultures. New York: Basic Books.

Koentjaraningrat. 1985. Pengantar Ilmu Antropologi. Jakarta: Aksara Baru.

Keesing, Roger. 1994. "Theories of Culture Revisited" dalam Borofsky, (ed.) Assessing Cultural Anthropology R. Pp. 301 -- 311. New York: McGraw-Hill, Inc.

Lee III, Orville. 1986. 'Observations on Anthropological Thinking About The Culture Concept; Clifford Geertz and Pierre Bourdieu'. Berkeley Journal of Sociology 33: 115.

Moore, Sally F. 1987. 'Explaining The Present: Theoretical Dilemmas in Processual Etnography', American Ethnologist. 14 (4); 727 -- 736.

Ohnuki-Tierney, Emiko. 1994. 'Structure, Event, and Historical Metaphor: Rice and Identities in Japanese history'. The Journal of Royal Anthropological Institute 1 (2).
Ortner, Sherry. 1984. 'Theory in Anthropology Since the Sixties', Comparative Studies in Societies and History (26): $126-166$.

Peacock, James L. 1981. 'The Third Stream; Weber, Persons, Geertz', Journal of Anthropological Society of Oxford. 12: 122 -- 129.

Picard, Michell. 1990. 'Cultural Tourism in Bali'. Indonesia. 49: 37 -- 74.

Said, Edward. 1977. Orientalism. New York: Pantheon.

Sahlins, Marshall. 1994. 'Goodbye to Tristes Tropique: Ethnography in the Context of Modem World History'. dalam R. Borofsky, (ed.) Assessing Cultural Anthropology. New York: Mc. Graw-Hill, Inc., halaman 377 -395.

Shankman, P. 1983. The Thick and The Thin: On The Interpretive Theoretical Program of Clifford Geertz. Current Anthropology. 25: 261 -- 279.

Suparlan, Parsudi. 1986. 'Kebudayaan dan Pembangunan'. Media IKA. 14: 2 -19.

Tamanoi, Mariko A. 1986. 'Women's Voices: Their Critique of The Anthropology of Japan'. Annual Review of Anthropology. 19: 17 -- 37.

Yamashita, Shinji. 1992. From 'Theater State' to 'Tourist Paradise' [dalam Bahasa Jepang]. Bulletin of The National Museum of Ethnology (17). 1: 1 -- 34. 